\title{
Introduction to the Special Feature on rebuilding fisheries and threatened communities
}

\author{
$\underline{\text { Rosemary E. Ommer }}^{1}$ and Barbara Neis ${ }^{2}$
}

\begin{abstract}
In this introductory essay to the Special Feature on rebuilding fisheries and threatened communities, we review the contributions of the researchers whose work is contained in this Special Feature. The essays are reviewed using the lens of the three questions that were posed by the Special Feature editors: Why is rebuilding so challenging? What is the relationship between fishery collapse/degradation and short- and long-term issues for food security, livelihoods, employment, and industrial and community resilience? How can we avoid situations in which the communities and people who may have contributed least to collapses/degradation end up paying the most for rebuilding and, indeed, may no longer be in a position where they can benefit from the results of their necessary sacrifices?
\end{abstract}

Key Words: changing industrial structures and organizational and industrial strategies from ocean to plate; geographic locus of key decisionmaking about fisheries management; higher-level governance actions; marine social-ecological interactions in the form of shifting ecologies

\section{INTRODUCTION: RATIONALE FOR THIS SPECIAL FEATURE}

The Community-University Research for Recovery Alliance (CURRA; http://www.curra.ca) was a seven-year initiative that used community-engaged research carried out in west coast Newfoundland fishery-dependent communities to help identify strategies for building ecologically, economically, and socially resilient fisheries and fishery communities. CURRA researchers from multiple disciplines worked with different methods and tools to investigate collaboratively a range of issues. These issues included the following: challenges related to rebuilding collapsed fisheries and threatened communities; the documentation of regional cod migration patterns; research on invasive species, species at risk, and lobster conservation initiatives; missed opportunities for synergies between fisheries and tourism and between fisheries and food security; young people's perceptions of fisheries and their home communities; and the effects of globalization and changing labor markets on current and future options for regional fisheries. CURRA researchers and community partners jointly developed community sustainability plans, as well as community radio capacity and programming.

The impetus for this Special Feature came from CURRA's "International Symposium on Rebuilding Collapsed Fisheries and Threatened Communities," held in October 2012. Earlier versions of some of the papers herein were presented there, and others were written after Ecology and Society accepted our Special Feature proposal. In our call for papers, we challenged authors to address one or more of the following three questions: Why is rebuilding so challenging? What is the relationship between fishery collapse/degradation and short- and long-term issues for food security, livelihoods, employment, and industrial and community resilience? How can we avoid situations in which the communities and people who may have contributed least to collapses/degradation end up paying the most for rebuilding and, indeed, may no longer be in a position where they can benefit from the results of their necessary sacrifices?

The Special Feature consists of 11 articles. Ten addressed the first question (Bennett et al. 2014, Blythe et al. 2014, Broderstad and
Eythórsson 2014, Dawe and Schneider 2014, Foley and McCay 2014, Johnsen and Hersoug 2014, Nayak et al. 2014, Paterson and Kainge 2014, Pinkerton et al. 2014, Power et al. 2014); nine addressed the second question either directly or implicitly (Bennett et al. 2014, Blythe et al. 2014, Brodestad and Eythórsson 2014, Foley and McCay 2014, Lowitt 2014, Nayak et al. 2014, Paterson and Kainge 2014, Pinkerton et al. 2014, Power et al. 2014); and eight implicitly addressed the last question (Bennett et al. 2014, Broderstad and Eythórsson 2014, Foley and McCay 2014, Johnsen and Hersoug 2014, Nayak et al. 2014, Paterson and Kainge 2014, Pinkerton et al. 2014, Power et al. 2014).

\section{UNDERLYING THEORY AND LITERATURE}

We do not review the wider literature because that is covered in the individual papers in this Special Feature. Here, we focus instead on the fundamental approach that underlies all these papers and discuss key generic issues in social-ecological thought, which has its roots in the work of Carl Folke, Fikret Berkes, and (more broadly) the Resilience Alliance (http://www.resalliance. org). It came into its own during the late 1990s and early 2000s as a result of two seminal texts, the first by Berkes and Folke (1998), which opened the door to "linking social and ecological systems", as that original volume was entitled, and a subsequent volume by Berkes, Colding, and Folke (2003) that addressed ways of (again, as entitled) "navigating social-ecological systems". Fundamental to that thinking and, thus, to the approach that has evolved from it, is what Perry and Ommer (2003) have called the 'iterative interdependence' of resource-dependent communities and the ecology that maintains and supports the resource (and by extension, larger scale regulatory frameworks and markets). Changes in one part of the social-ecological system affect the other parts, and the resultant response of those other parts in turn has an effect on the first part, and so on, iteratively.

The adaptation of the social-ecological systems approach, so that it can be used to analyze marine fisheries, arose out of its application in coastal and oceans research. It became part of the research approach of the Global Ocean Ecosystem Dynamics international research group (GLOBEC, supported by the United Nations, the International Geosphere-Biosphere Programme, 
and the Scientific Community on Oceanic Research), and many other research initiatives, of which the Canadian Coasts Under Stress project (Ommer and Team 2007), predecessor of CURRA, and CURRA itself were two. In 2008, Fikret Berkes, in a keynote opening address to a GLOBEC-sponsored conference on world fisheries, specifically applied social-ecological thinking to marine fisheries (Berkes 2011). Also in 2011, a team of researchers drawn from GLOBEC's "Focus Four" on human dimensions (which included scholars from Coasts Under Stress and CURRA), sought to see if some overall dynamics that influenced the adaptive capacity of social-ecological systems could be identified. Building on earlier work by Perry and Ommer (2003) on the appropriate use of geographical and temporal scales in the management of marine resources, and on the work of a fully interdisciplinary Canadian team of researchers who explicitly used a social-ecological approach to natural resource-dependent communities in Canada (Ommer and Team 2007), the paper they produced drew on four case studies from different parts of the world to systematize adaptive capacity in marine social-ecological systems (Perry et al. 2011). They produced a schematic diagram (Fig. 1) of marine ecological and human social fishing system responses to short- and long-duration stresses under globalization. These case studies suggested that, "with a short duration stress, ecological and human fishing systems are able to respond with both short-term coping and longer-term adaptive responses to compensate for the changes caused by the stress." In contrast, with a longer-duration stress, the short-term coping responses of both systems become exhausted, leaving only the longer-term adaptive responses." The result, they concluded, was "decreasing flexibility in the human fishing system and increasing variability in the ecological system" (Perry et al. 2011:444).

This identification of "coping responses at short time scales and adaptive responses at longer time scales" (Perry et al. 2011:446) is important. However, it needs to be tested across a much wider range of case studies, as does their conclusion that "[c]oping responses had broadly similar characteristics in both ecological systems and fishing societies, whereas adaptive responses were different, with a broader range of behaviours in fishing societies. Persistent stresses may result in more rapid capacities to respond by the ecological system but reduced response capabilities in human fishing societies" (Perry et al. 2011:446).

The implications for management policies are significant, for they will need to "maintain the diversities of responses, at short- and longer-time scales, in both marine ecological and human fishing societies." Finally, they observed that "[e]cosystem-based management...needs to be expanded to consider the interdependent social part of these social-ecological systems," while any attempts to address such systems' vulnerabilities "must also adopt a multi-scale approach" and involve both the natural and social sciences in "research, analyses and governance" of marine social-ecological systems. Helpful as this analysis is, it was based on only four case studies. What is needed to recognize human agency in such linked systems sustainability analysis are "contextualized, place-based, social-ecological system cases.... Universal models...do not serve well to understand local level dynamics" (Berkes 2011:23).
Fig. 1. Coping responses at short-time scales (A) and adaptive responses at longer-time scales (B). Recreated from Perry et al. (2011).
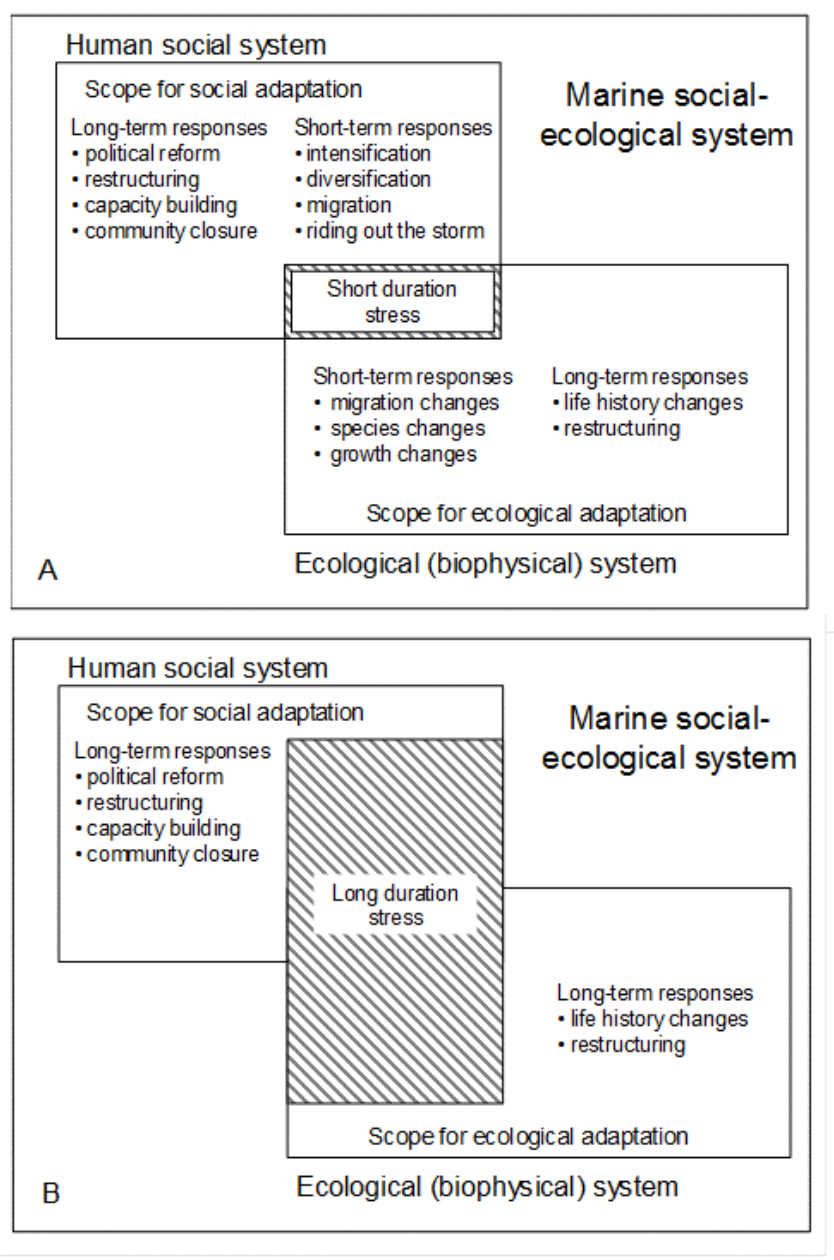

Stock collapses and related fishery closures are one such locallevel set of dynamics, relatively speaking, and they almost always generate multiple, longer duration, interactive stressors. This is why rebuilding collapsed social-ecological systems comprising both fisheries and threatened communities is such a wicked problem (Khan and Neis 2010). Rebuilding is particularly challenging when the objective is to produce resilient fisheries that achieve not only ecological but also social and economic resilience.

These days, resilience in coastal fishing communities around the world far too often depends on the rebuilding of damaged stocks and communities that are in deep trouble. If such rebuilding is to be done successfully, it will require detailed understanding of local and larger scale social-ecological complexities. Only then will policy-makers have real grounds for confidence in the ameliorative governance frameworks they create, whose goal should be to rebuild damaged social-ecological systems in such a 
way that local realities are addressed and, hence, real long-term resilience is achieved. As Neis et al. (2014:59) comment in a recent policy paper that arose out of CURRA and was produced as a result of significant input from representatives of many parts of the fishing society that CURRA studied,

There are many reasons why we must not lose our small and medium-scale fisheries. The most important of these is that the majority of them are still contributing in crucial ways to the lives and livelihoods of thousands of people ... and to the governance of thousands of square miles of ocean resources and thousands of miles of coastline as well as hundreds of wharves and other types of infrastructure. But these fisheries ... need vibrant communities and multiple and diverse opportunities for marketing their catches, be that locally, provincially, nationally or internationally. Opportunities must include not just commodity markets, but also the development of some processing capacity and the related targeting of high quality, traceable products to different market niches (emphasis [plain font] in original).

Comparative analyses of findings from local case studies can support the establishment of general principles under which appropriate governance policies can be developed with sensitivity to both the local and the global. At the same time, "since different fisheries in the world are increasingly set within the context of a globalized trade in fish products, and an increasingly globalized catching technology, what the world's fishing nations need to create is a sensitive interplay between place-based cases and global trends" (Ommer and Perry 2011:403). This Special Feature follows that admonition. It builds on the social-ecological approach and extends current thinking by presenting a range of contextualized, placed-based case studies from different parts of the world that expand and illuminate the current state of understanding of marine social-ecological systems.

\section{THEMES COVERED IN THIS SPECIAL FEATURE}

Such, then, are the theoretical and research literature generic roots of the marine social-ecological research presented in this Special Feature. These contributions examine a significant number of local-level dynamics ranging from issues that arise from climate and modernization stresses, through the impacts of poverty and politics, and the place of local knowledge in fisheries rebuilding. They also explore the potential marginalization of youth and their related perceptions of rebuilding fisheries, species at risk and other conservation initiatives, threatened fishing communities and their co-dependent ecosystems, and issues associated with changes in policy, food security, and livelihoods in the wake of stock collapse and fisheries rebuilding.

All of these dynamics come into play in the papers that address the first question we posed to the authors: Why is rebuilding so challenging? Blythe et al. (2014), considering small-scale fisheries and their associated communities in Mozambique under the stresses of modernization and climate change, uncover adaptive responses of either diversification or fishery intensification, coupled with financial loans and community organization. Importantly, they show that limitations on assets reduce adaptive capacity, as does competition within the community. Moreover, their observation that people and communities can adapt, but that the magnitude and speed of change make such adaptation very challenging, is a crucial point.

Bennett et al. (2014), looking at adaptive strategies on the Andaman coast, point to the multiple challenges associated with overfishing, coastal development, pollution, and the creation of marine protected areas and other conservation measures. They identify three categories of response: adaptation, reaction, and coping. They show that adaptation is productive; reaction is an unplanned response to stressors; and they see coping as passive acceptance, resulting in no behavioral change. Most communities, they find, are merely coping with stress, frequently out of a lack of knowledge and understanding of what is happening. They suggest a range of interventions that could help, emphasizing the importance of flexibility and diversity of response, and (like Blythe et al. 2014) the need for access to sufficient assets, better governance, and leadership.

Broderstad and Eythórsson (2014) look at the challenges of change (including climate change) in two Norwegian fjords. They also point to coping as a strategy, including the diversification of the local economy, and emphasize active strategies such as the improvement of capital assets, seeing those as very important. They note too that ecological change will affect the choice of responses available. Significantly, they indicate the role of governance as vital to building resilience in fishing communities because it can ensure continued access to the resource base. Finally, like Bennett et al. (2014), they point to flexibility as crucial to any long-term strategy and observe how climate change can be a factor for good or ill, depending on the nature of the ecosystem shift that it triggers.

Johnsen and Hersoug (2014), in a second Norwegian study, discuss the complexities and challenges of power structures and local (versus global) control. In a potent argument for the principle of subsidiarity (control of fishery governance by those adjacent to the resource), they recognize that this is an ideal rather than an easily achievable outcome under current conditions of globalization and the consequent focus of national governments on the international marketplace. They discuss the importance of defining the spatial properties of the resource, arguing that mapping identifies a fishing area as locally governable because it stabilizes its existence and allows municipalities to make a cogent claim for management power.

Fisheries collapses are associated with a heightened risk of extinction, and successful rebuilding of stocks requires institutional changes that are designed to protect species at risk. In this respect, Dawe and Schneider (2014) provide an extremely useful analysis of how local ecological knowledge can be used with stock assessment science to provide nuanced responses to data observations of fish listed in the Species at Risk Act under changing conditions in eastern Canada. They address the challenge of how to bring local and scientific voices together, in a discussion that covers the challenges of scale differences and the concurrence (or otherwise) of empirical data. Paterson and Kainge (2014) focus on the possibility of combining local ecological knowledge insights with fisheries science, this time investigating the local knowledge of fishing trawler captains in the industrial blue water Namibian hake fishery. They discuss the challenges involved in understanding complex ecological systems 
and the nuanced analyses that are possible when such local knowledge is accepted as a regular part of stock assessment science practice. Governance challenges are also discussed.

Using case studies of small-scale fisheries located in India and Brazil, Nayak et al. (2014) show how "poverty, institutional processes, and environmental degradation are linked in complex, interactive ways." They use a social-ecological systems approach to illustrate how adding environmental change to a sociopolitical-institutional typology of factors leading to poverty can improve our understanding of poverty dynamics in small-scale fisheries. Starting from the point of view of local people, including marginal populations, their research shows that social-ecological processes are important factors in impoverishment. These processes include power dynamics that disconnect already vulnerable small-scale fishers from access to their fisheries and from the basis for their identities, thus leading, in some cases, to their displacement.

Pinkerton et al. (2014) report on the efforts of aboriginal and nonaboriginal fishery organizations in the fisheries of coastal British Columbia, Canada, to rebuild local and regional institutions that were badly eroded by external management initiatives and loss of access to resources. They use these case studies to identify some prerequisites for successful rebuilding, pointing to the complexities of required access to power in efforts to establish and develop co-management fishing practices. They suggest that strong place identity and community values help when navigating these complexities, with strong leadership and consensus among groups leading to enhanced conservation and increased power in shaping policy.

The next question we posed to the authors is also covered by many of the papers: What is the relationship between fishery collapses and short- and long-term issues for food security, livelihoods and employment, and industrial and community resilience? Here, some contributions are particularly insightful, such as Bennett et al.'s (2014) work on the Andaman coast, which shows the strong linkages between food security, livelihoods, employment, education, and good governance. Broderstad and Eythórsson (2014) do likewise with ecosystem shifts under climate change, and emphasize, in particular, the importance of the links between region-level governance and the ability to generate helpful options under stress. Nayak et al. (2014), by contrast, show how failures in governance and a lack of voice in decision-making circles can destroy livelihoods, food security, and community resilience.

One of the consequences of global overfishing and some devastating fisheries collapses has been greater engagement of environmental nongovernmental organizations in fisheries governance. Certification schemes are among the initiatives these groups have helped to devise in an effort to support stock recovery and to prevent future collapses. However, as currently designed, in some contexts, these schemes exacerbate threats to the fisheries themselves, particularly small-scale fisheries. Drawing on insights from two case studies of the involvement of cooperative-based small-scale fisheries in Canada and Mexico, Foley and McCay (2014) argue that certification and eco-labeling initiatives privatize fisheries governance in largely unexamined ways. In the process, they "embed new social relations and institutions in existing social-ecological systems", bringing with them the potential for enhanced conflict, as well as cooperation. A related risk is the potential marginalization of small-scale fisheries and their associated communities when they have limited resources for certification and lack control over the governance of fish stocks shared with other groups, resulting in a potential "tragedy of certification." Marine Steward Certification and eco-labeling initiatives are often based on the creation of new, large-scale, standardized institutional regimes. Pinkerton et al. (2014) do parallel work in their essay on co-management structures and how these carry the potential (or otherwise) for vibrant community livelihoods and long-term resilience. They focus on efforts to rebuild local and regional institutions by creating new ones, and reinventing, reactivating, or re-positioning old ones, with the goal of addressing a broad range of risks.

Power et al. (2014) extend current thinking on livelihoods in fishing communities to help focus on a range of processes that can shape or distort youth's ideas of the options available to them for their futures. Working in western Newfoundland, a region hard hit by the collapse of regional cod stocks and prolonged rebuilding (extending over $>20$ years), they explore the perceptions that young people have of local fisheries and their home communities. They also consider young people's assessments of what these places have to offer and explain the impacts of fisheries collapses and prolonged rebuilding processes on current and future generations. Lowitt (2014), considering changing livelihoods over time in the same post-collapse context, looks at the cultural framing of fish as part of community diets in the past and present, showing how a regional "foodscape" and community food security can alter as ecosystems shift, food sources change, and cultural norms adjust.

The last question we posed is: How can we avoid situations in which those who may have contributed least to collapses end up paying the most for rebuilding and indeed may no longer be in a position where they can benefit from the necessary sacrifices? In many ways the most subtle question, it also proves to be the most difficult to address, and those authors who deal with it do so implicitly.

The central concern here is with geographical and temporal scale and their interactions with the social organization of fisheries, fishery-dependent regions, and power dynamics. Bennett et al. (2014), Broderstad and Eythórsson (2014), Foley and McCay (2014), Johnsen and Hersoug (2014), Nayak et al. (2014), Paterson and Kainge (2014), Power et al. (2014), and Pinkerton et al. (2014) examine issues of complexity, class exploitation, use and property rights, levels and scales of governance, youth, relationships between local and scientific knowledge, often dwindling access to resources, and control over management of local and First Nation communities. They share concerns that many communities and people (who are on the frontlines grappling with major shifts in the social-ecological systems of which they are a part) are at risk of having their vulnerability enhanced by management initiatives and organizational and market changes triggered by, or concurrent with, these changes. All of these essays show that there are winners and losers associated with different strategies for dealing with major changes such as stock collapses. Many of the losers end up struggling with the direct impacts of change, particularly temporal and organizational mismatches between their needs and options. The extent to which such initial losers are resilient to these interacting effects and are able to access or 
build opportunity spaces varies across and within fisheries and over time. This in turn influences whether and how communities are and will be positioned to benefit from the inevitable sacrifices that come from the collapse and subsequent rebuilding of stocks.

These essays together show that resilience can be either supported and enhanced or seriously constrained by social-ecological interactions in the form of shifting ecologies, higher-level governance actions, the geographical locus of key decisionmaking about fisheries management, changing industrial structures, and organizational and industrial strategies from ocean to plate. That said, it is Broderstad and Eythórsson (2014), Johnsen and Hersoug (2014), Bennett et al. (2014), Pinkerton et al. (2014), and Foley and McCay (2014) who concretely address the issue of how power is tied to geographical and temporal scale and management, and only Bennett et al. (2014) and Pinkerton et al. (2014) expressly offer recommendations for alleviating some of the injustices that can (and often do) result from these kinds of scale and power disconnects.

\section{CONCLUSION}

"Building the social into the ecological requires more than adding on a couple of variables, because social power is multidimensional and operates at multiple scales, especially during periods of rapid change" (Ommer and Perry 2011:406). This complexity of marine social-ecological systems is brought under the spotlight in this Special Feature, as are (it follows) the difficulties such complexity brings to adaptive capacity. Yet it is that very complexity, seen as opening options and hence as a potential source of resilience, that creates flexibility and points to a way forward for at least some of the communities examined in these case studies.

The overarching contribution of this Special Feature, in our view, is to put flesh (so to speak) on the relatively abstract set of principles that the Perry et al. (2011) paper sought to establish. These essays underline just how difficult it can be to address apparently obvious issues such as inappropriate management regimes or lack of appreciation of matters as apparently (but not actually) distinct as understanding the value of the knowledge that ship captains have of fish behavior and the crucial nature of poverty and class in stifling adaptive capacity. Work such as that featured here enlarges and enhances the vision of social-ecological systems. It illustrates powerfully how, despite differing situations and locations, social-ecological systems are interdependent entities whose capacity to adapt is always contingent, needing support and requiring to be valued as (among other things) the powerful force for global economic equity and environmental and cultural survival that these papers show them to be.

Responses to this article can be read online at: http://www.ecologyandsociety.org/issues/responses. $\mathrm{php/6960}$

\section{Acknowledgments:}

We thank the Social Sciences and Humanities research Council of Canada for funding part of the research contained in this Special Feature.

\section{LITERATURE CITED}

Bennett, N. J., P. Dearden, G. Murray, and A. Kadfak. 2014. The capacity to adapt? Communities in a changing climate, environment, and economy on the northern Andaman coast of Thailand. Ecology and Society 19(2): 5. http://dx.doi.org/10.5751/ ES-06315-190205

Berkes, F. 2011. Restoring unity: the concept of marine socialecological systems. Pages 9-28 in R. E. Ommer, R. I. Perry, K. Cochrane, and P. Cury, editors. World fisheries: a social-ecological analysis. Wiley-Blackwell, Oxford, UK. http://dx.doi. org/10.1002/9781444392241.ch2

Berkes, F., J. Colding, and C. Folke, editors. 2003. Navigating social-ecological systems: building resilience for complexity and change. Cambridge University Press, Cambridge, UK. http://dx. doi.org/10.1017/CBO9780511541957

Berkes, F., and C. Folke, editors. 1998. Linking social and ecological systems: management practices and social mechanisms for building resilience. Cambridge University Press, Cambridge, UK.

Blythe, J. L., G. Murray, and M. Flaherty. 2014. Strengthening threatened communities through adaptation: insights from coastal Mozambique. Ecology and Society 19(2): 6. http://dx.doi. org/10.5751/ES-06408-190206

Broderstad, E. G., and E. Eythórsson. 2014. Resilient communities? Collapse and recovery of a social-ecological system in Arctic Norway. Ecology and Society 19(3): 1. http://dx.doi. org/10.5751/ES-06533-190301

Dawe, J., and D. Schneider. 2014. Consilient knowledge in fisheries: a case study of three species of wolffish (Anarhichadidae) listed under the Canadian Species at Risk Act. Ecology and Society 19(3): 26. http://dx.doi.org/10.5751/ ES-06674-190326

Khan, A. S., and B. Neis. 2010. The building imperative in fisheries: clumsy solutions for a wicked problem. Progress in Oceanography 87(1-4):347-356. http://dx.doi.org/10.1016/j. pocean.2010.09.012

Lowitt, K. N. 2014. A coastal foodscape: examining the relationship between changing fisheries and community food security on the west coast of Newfoundland. Ecology and Society, 19(3): 48. http://dx.doi.org/10.5751/ES-06498-190348

Foley, P., and B. McCay. 2014. Certifying the commons: ecocertification, privatization, and collective action. Ecology and Society 19(2): 28. http://dx.doi.org/10.5751/ES-06459-190228

Johnsen, J. P., and B. Hersoug. 2014. Local empowerment through the creation of coastal space? Ecology and Society 19(2): 60. http:// dx.doi.org/10.5751/ES-06465-190260

Nayak, P. K., L. E. Oliveira, and F. Berkes. 2014. Resource degradation, marginalization, and poverty in small-scale fisheries: threats to social-ecological resilience in India and Brazil. Ecology and Society 19(2): 73. http://dx.doi.org/10.5751/ ES-06656-190273

Neis, B., R. E. Ommer, and P. Hall. 2014. Moving forward: building economically, socially and ecologically resilient fisheries and coastal communities. Community-University Research for 
Recovery Alliance, St. John's, Canada. [online] URL: http://www. curra.ca/documents/CURRA-Booklet-FINAL-WebRes.pdf.

Ommer, R. E., and R. I. Perry. 2011. Conclusion: hierarchy, power, and potential regime shifts in marine social-ecological systems. Pages 403-406 in R. E. Ommer, R. I. Perry, K. Cochrane, and P. Cury, editors. World fisheries: a social-ecological analysis. WileyBlackwell, Oxford, UK. http://dx.doi.org/10.1002/9781444392241. $\underline{\operatorname{ch} 24}$

Ommer, R. E., R. I. Perry, K. Cochrane, and P. Cury, editors. 2011. World fisheries: a social-ecological analysis. WileyBlackwell, Oxford, UK. http://dx.doi.org/10.1002/9781444392241

Ommer, R. E., and Team. 2007. Coasts under stress: restructuring and social-ecological health. McGill-Queen's University Press, Montreal and Kingston, Canada.

Paterson, B., and P. Kainge. 2014. Rebuilding the Namibian hake fishery: a case for collaboration between scientists and fishermen. Ecology and Society 19(2):49. http://dx.doi.org/10.5751/ ES-06370-190249

Perry, R. I., and R. E. Ommer. 2003. Scale issues in marine ecosystems and human interactions. Fisheries Oceanography 12 (4-5):513-522. http://dx.doi.org/10.1046/j.1365-2419.2003.00254. $\underline{\mathrm{X}}$

Perry, R. I., R. E. Ommer, M. Barange, S. Jentoft, B. Neis, and U. R. Sumaila. 2011. Marine social-ecological responses to environmental change and the impacts of globalization. Fish and Fisheries 12(4):427-450. http://dx.doi.org/10.1111/j.1467-2979.2010.00402.

$\underline{\mathrm{X}}$

Pinkerton, E., E. Angel, N. Ladell, P. Williams, M. Nicolson, J. Thorkelson, and H. Clifton. 2014. Local and regional strategies for rebuilding fisheries management institutions in coastal British Columbia: what components of comanagement are most critical? Ecology and Society 19(2): 72. http://dx.doi.org/10.5751/ ES-06489-190272

Power, N. G., M. E. Norman, and K. Dupré. 2014. "The fishery went away": The impacts of long-term fishery closures on young people's experience and perception of fisheries employment in Newfoundland coastal communities. Ecology and Society 19(3): 6. http://dx.doi.org/10.5751/ES-06693-190306 